\title{
Elevated erythrocyte sedimentation rate is associated with metastatic disease and worse survival in patients with cutaneous malignant melanoma
}

\author{
FARUK TAS and KAYHAN ERTURK \\ Department of Medical Oncology, Institute of Oncology, Istanbul University, Istanbul 34390, Turkey
}

Received July 12, 2017; Accepted October 2, 2017

DOI: $10.3892 /$ mco.2017.1440

\begin{abstract}
Elevated erythrocyte sedimentation rate (ESR) is common in cancer patients and it may affect survival. However, its clinical role and prognostic significance remain unknown in melanoma patients. The objective of the present study was to determine the clinical significance of the ESR levels in cutaneous melanoma patients. A total of 139 cutaneous melanoma patients were enrolled in this study and were retrospectively investigated. The median age of the patients was 52 years (range, 16-88 years). The median ESR was $22 \mathrm{~mm} / \mathrm{h}$ (range, 2-122 mm/h). Significant differences in ESR were found to be associated with sex, histology, blood hemoglobin level, lactate dehydrogenase $(\mathrm{LDH})$ and metastatic disease. Female patients $(\mathrm{P}=0.006)$ and those with nodular histology $(\mathrm{P}=0.005)$, low hemoglobin concentration $(\mathrm{P}<0.001)$, higher LDH levels $(\mathrm{P}=0.003)$ and metastatic disease $(\mathrm{P}<0.001)$ were more likely to have elevated ESR levels. However, ESR was not found to be significantly associated with age, site of lesion, or pathological indicators, including Clark's level of invasion, Breslow's depth, mitotic rate, ulceration, vertical growth phase, tumor-infiltrating lymphocytes, regression, neurotropism, lymphovascular invasion and BRAF (V600E) mutation $(\mathrm{P}>0.05)$. ESR was also not associated with lymph node involvement $(\mathrm{P}=0.188)$ or responsiveness to chemotherapy $(\mathrm{P}=0.390)$. However, ESR was found to be significantly associated with outcome; patients with increased ESR had worse survival compared with those with normal values (hazard ratio $=2.033 ; 95 \%$ confidence interval: 1.156-3.577; $\mathrm{P}=0.012)$. In conclusion, elevated ESR was found to be associated with metastatic disease and
\end{abstract}

Correspondence to: Dr Faruk Tas, Department of Medical Oncology, Institute of Oncology, Istanbul University, 118 Millet Street, Capa, Istanbul 34390, Turkey

E-mail: faruktas2002@yahoo.com

Key words: erythrocyte sedimentation rate, melanoma, prognosis, survival was also found to be a prognostic factor adversely affecting survival in patients with cutaneous melanoma.

\section{Introduction}

It has been demonstrated that there is an association between chronic inflammation and carcinogenesis (1), and that subclinical or even undetectable inflammation may be as significant as chronic inflammation in increased cancer risk, cancer development and progression (1). Chronic inflammation may promote excessive cell proliferation and activate a cascade of cellular events, promoting tumor cell growth (2). Furthermore, tumor progression per se may also stimulate host immune response and inflammation.

Erythrocyte sedimentation rate (ESR) is the most widely used laboratory test for evaluating the inflammatory status in clinical practice, including infection, autoimmune and malignant diseases (3). Elevated ESR is frequently encountered in patients with cancer. The outcome in various malignancies depends on the type of the underlying disorder, the stage and duration of the disease, and the regimen and intensity of the antitumor treatment. In addition, an elevated ESR level has also been identified as a prognostic factor adversely affecting survival in cancer patients (2-8). A number of studies indicated that an increased ESR level is associated with worse survival; patients with higher ESR values in various malignancies, including colorectal cancer (2), renal cell cancer (4), head and neck cancer (5), soft tissue sarcoma (6), breast cancer (7), glioma (8) and prostate cancer (9), had a shorter survival compared with those with normal ESR levels.

Although there have been sufficient data on other types of tumors, to the best of our knowledge, the prognostic value of ESR in melanoma patients has not been adequately investigated $(10,11)$ and the significance of elevated ESR levels in melanoma patients has not been fully elucidated. However, increased ESR levels have been identified as an adverse prognostic factor for survival in melanoma patients as a secondary finding when different parameters were investigated in our previously published trials (12-15).

In the present study, the ESR levels were evaluated in cutaneous melanoma patients, and the associations with disease prognosis and various known clinical variables were determined. 


\section{Patients and methods}

Patients. A total of 139 adult patients with histologically confirmed cutaneous melanoma in whom ESR was determined were included in the present analysis and were retrospectively investigated. The patient records were retrieved from the cancer registry of the Institute of Oncology, University of Istanbul (Istanbul, Turkey) for review of the clinicopathological factors and patient survival. The patients were treated and followed-up according to standard international guidelines, such as National Comprehensive Cancer Network (https://www.nccn.org/patients/guidelines/melanoma/) and European Society for Medical Oncology (http://www.esmo .org/Guidelines/Melanoma) guidelines.

The ESR values of the patients were determined at first admission by the standard Westergren method $(16,17)$. The study protocol was reviewed and approved by the local Ethics Committee.

Statistical analysis. Comparisons between clinicopathological characteristics and ESR values were performed using the Mann-Whitney U test, independent samples t-test and logistic regression test. Receiver operating characteristic curves were used to define the cut-off value of ESR levels for survival analysis. Kaplan-Meier analysis was used for estimation of patient survival and differences in outcomes were assessed using log-rank statistics. A P-value of $\leq 0.05$ was considered to indicate statistically significant differences.

\section{Results}

Patient characteristics. A total of 139 cutaneous melanoma patients were enrolled in the present study. The median age of the patients was 52 years (range, 16-88 years). The demographic and clinicopathological characteristics are summarized in Table I. The median value of ESR values of the patients was $22 \mathrm{~mm} / \mathrm{h}$ (range, $2-122 \mathrm{~mm} / \mathrm{h}$ ). Significant differences in ESR were only found in association with sex, histology, blood hemoglobin level, lactate dehydrogenase (LDH) levels and metastatic disease (Table I). Female patients $(\mathrm{P}=0.006)$ and those with nodular histology $(\mathrm{P}=0.005)$, low hemoglobin concentration $(\mathrm{P}<0.001)$, higher LDH levels $(\mathrm{P}=0.003)$ and metastatic disease $(\mathrm{P}<0.001)$ were more likely to have elevated ESR values. However, the ESR levels were not found to be significantly associated with age, site of lesion, or pathological indicators such as Clark's level of invasion, Breslow's depth, mitotic rate, ulceration, vertical growth phase, tumor-infiltrating lymphocytes, regression, neurotropism, lymphovascular invasion and BRAF (V600E) mutation $(\mathrm{P}>0.05)$. ESR was also not associated with lymph node involvement $(\mathrm{P}=0.188)$ or responsiveness to chemotherapy $(\mathrm{P}=0.390)$.

Effect of elevated ESR on survival. When survival analyses of possible clinicopathological variables affecting outcome were performed, nodular histology $(\mathrm{P}=0.043)$, high mitotic rate $(\mathrm{P}=0.004)$, presence of ulceration $(\mathrm{P}=0.034)$, presence of lymphovascular invasion $(\mathrm{P}<0.001)$, increased serum $\mathrm{LDH}$ level $(\mathrm{P}<0.001)$, lymph node involvement $(\mathrm{P}=0.005)$, multiple node involvement $(\mathrm{P}=0.010)$, distant metastasis $(\mathrm{P}<0.001)$ and

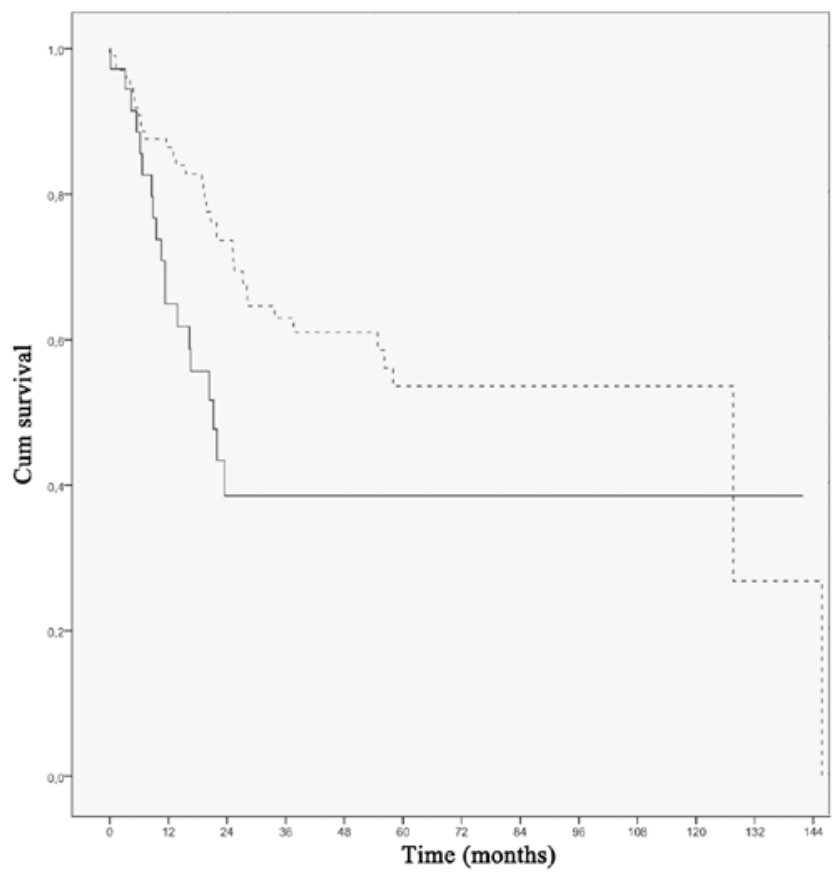

Figure 1. Overall survival curves in melanoma patients according to ESR ( $<35$ vs. $\geq 35 \mathrm{~mm} / \mathrm{h} ; \mathrm{P}=0.012)$. Dotted line, $<35 \mathrm{~mm} / \mathrm{h}$; straight line, $\geq 35 \mathrm{~mm} / \mathrm{h}$. ESR, erythrocyte sedimentation rate.

failure to respond to chemotherapy $(\mathrm{P}=0.002)$ were found to be poor prognostic factors for overall survival (Table II). ESR was found to be significantly associated with outcome, with patients with elevated ESR exhibiting worse survival compared with those with normal ESR values $(\mathrm{P}=0.012)$ (Table II, Fig. 1).

\section{Discussion}

The aim of the present study was to evaluate the prognostic value of ESR elevation focusing specifically on cutaneous melanoma patients. The study analyzed 139 melanoma patients, including all disease stages, which, to the best of our knowledge, is the largest population-based sample size from a single institution to date.

At the time of the analysis, to our knowledge, only a limited number of studies had focused on the prognostic value of the ESR level in cutaneous melanoma patients $(10,11)$. In the Norwegian Radium Hospital, 177 metastatic melanoma patients treated with various chemotherapy regimens were included in a regression analysis of prognostic factors (10). Multivariate analysis identified ESR $>15 \mathrm{~mm} / \mathrm{h}$ as a significant prognostic factor indicating short survival with a low probability of surviving for 3 months, whereas patients with normal ESR values had a median survival of 11.5 months, with $94 \%$ surviving for 3 months. In another study, 71 patients with metastatic disease were included (11). The serum ESR levels were significantly elevated in patients with progressive disease. On logistic regression analysis, ESR was found to be of low specificity.

The present study revealed that an elevated ESR level was associated with metastatic disease, but not lymph node involvement. ESR level at diagnosis was a prognostic factor 
Table I. Patient/disease characteristics and correlations between ESR and various clinicopathological variables.

\begin{tabular}{|c|c|c|c|c|}
\hline Variables & $\mathrm{n}$ & ESR $(\mathrm{mm} / \mathrm{h})$, median (range) & $\mathrm{HR}(95 \% \mathrm{CI})$ & P-value \\
\hline No. of patients & 139 & $22(2-122)$ & & \\
\hline Age (years) & & & $1.001(0.985-1.018)$ & 0.162 \\
\hline$<50$ & 64 & $20.5(2-122)$ & & \\
\hline$\geq 50$ & 75 & $23(3-83)$ & & \\
\hline Sex & & & $1.017(0.999-1.035)$ & 0.006 \\
\hline Male & 87 & $19(2-122)$ & & \\
\hline Female & 52 & $30(5-83)$ & & \\
\hline Site of lesion & & & $1.005(0.984-1.026)$ & 0.652 \\
\hline Axial & 69 & $22(3-70)$ & & \\
\hline Extremities & 58 & $19.5(2-83)$ & & \\
\hline Histopathology & & & $0.978(0.953-1.003)$ & 0.005 \\
\hline Nodular & 24 & $27(10-70)$ & & \\
\hline Others & 74 & $19.5(2-83)$ & & \\
\hline Clark's level & & & $1.012(0.979-1.047)$ & 0.280 \\
\hline I-III & 19 & $16(3-63)$ & & \\
\hline IV-V & 83 & $21(5-83)$ & & \\
\hline Breslow's thickness, mm & & & $1.016(0.981-1.051)$ & 0.398 \\
\hline$<2$ & 20 & $18.5(3-62)$ & & \\
\hline$\geq 2$ & 85 & $21(3-83)$ & & \\
\hline Mitotic rate, $\mathrm{n} / \mathrm{mm}^{2}$ & & & $1.011(0.986-1.036)$ & 0.387 \\
\hline$\leq 3$ & 47 & $20(3-83)$ & & \\
\hline$>3$ & 50 & $21(7-83)$ & & \\
\hline Ulceration & & & $1.028(0.999-1.059)$ & 0.115 \\
\hline Absent & 38 & $20(3-52)$ & & \\
\hline Present & 62 & $22(3-83)$ & & \\
\hline Neurotropism & & & $1.013(0.953-1.075)$ & 0.690 \\
\hline Absent & 58 & $20.5(3-83)$ & & \\
\hline Present & 3 & $25(22-40)$ & & \\
\hline Vertical growth phase & & & $0.999(0.925-1.079)$ & 0.988 \\
\hline Absent & 3 & $15(10-42)$ & & \\
\hline Present & 60 & $20(3-83)$ & & \\
\hline Lymphovascular invasion & & & $1.026(0.994-1.060)$ & 0.107 \\
\hline Absent & 72 & $19.5(3-66)$ & & \\
\hline Present & 15 & $26(5-83)$ & & \\
\hline Tumor-infiltrating lymphocytes & & & $1.008(0.978-1.039)$ & 0.599 \\
\hline Absent & 23 & $16(3-83)$ & & \\
\hline Present & 70 & $21.5(3-83)$ & & \\
\hline Regression & & & $1.012(0.987-1.039)$ & 0.350 \\
\hline Absent & 61 & $20(3-66)$ & & \\
\hline Present & 28 & $21(7-83)$ & & \\
\hline BRAF (V600E) mutation & & & $0.972(0.931-1.015)$ & 0.171 \\
\hline Negative & 12 & $27(7-96)$ & & \\
\hline Positive & 15 & $22(6-63)$ & & \\
\hline Hemoglobin level & & & $0.953(0.931-0.975)$ & $<0.001$ \\
\hline Low & 36 & $35.5(10-122)$ & & \\
\hline Normal & 98 & $18(2-83)$ & & \\
\hline Serum lactate dehydrogenase & & & $1.033(1.012-1.055)$ & 0.003 \\
\hline Normal & 109 & $21(2-83)$ & & \\
\hline High & 24 & $34(11-122)$ & & \\
\hline
\end{tabular}


Table I. Continued.

\begin{tabular}{|c|c|c|c|c|}
\hline Variables & $\mathrm{n}$ & ESR $(\mathrm{mm} / \mathrm{h})$, median (range) & $\operatorname{HR}(95 \% \mathrm{CI})$ & P-value \\
\hline Lymph node metastasis & & & $1.023(0.994-1.054)$ & 0.188 \\
\hline No & 35 & $18(2-52)$ & & \\
\hline Yes & 68 & $22(5-83)$ & & \\
\hline No. of lymph node metastasis & & & $1.028(0.996-1.060)$ & 0.078 \\
\hline 1 & 37 & $21(5-51)$ & & \\
\hline$\geq 2$ & 30 & $22(5-83)$ & & \\
\hline Metastatic stage (M1) & & & $1.044(1.022-1.066)$ & $<0.001$ \\
\hline No & 99 & $18(2-75)$ & & \\
\hline Yes & 40 & $31.5(2-122)$ & & \\
\hline Stage of metastatic disease & & & $0.989(0.965-1.014)$ & 0.401 \\
\hline M1a-b & 14 & $37(15-96)$ & & \\
\hline M1c & 26 & $31.5(2-122)$ & & \\
\hline Response to chemotherapy & & & $0.987(0.959-1.016)$ & 0.390 \\
\hline No & 20 & $38(15-122)$ & & \\
\hline Yes & 14 & $31.5(6-83)$ & & \\
\hline
\end{tabular}

ESR, erythrocyte sedimentation rate; HR, hazard ratio; CI, confidence interval.

Table II. Analysis of variables in association with overall survival.

\begin{tabular}{|c|c|c|}
\hline Variables & $\operatorname{HR}(95 \% \mathrm{CI})$ & P-value \\
\hline Age & $1.037(0.607-1.772)$ & 0.893 \\
\hline Sex & $0.677(0.377-1.215)$ & 0.191 \\
\hline Site of lesion & $0.608(0.332-1.115)$ & 0.104 \\
\hline Histology & $0.457(0.211-0.993)$ & 0.043 \\
\hline Clark's level & $2.054(0.717-5.881)$ & 0.171 \\
\hline Breslow's thickness & $1.824(0.702-4.743)$ & 0.211 \\
\hline Ulceration & $2.362(1.045-5.341)$ & 0.034 \\
\hline Mitotic rate & $2.972(1.354-6.523)$ & 0.004 \\
\hline Neurotropism & $2.430(0.314-18.77)$ & 0.379 \\
\hline Vertical growth phase & $22.06(0.001-48851)$ & 0.356 \\
\hline Lymphovascular invasion & $5.681(2.432-13.27)$ & $<0.001$ \\
\hline $\begin{array}{l}\text { Tumor-infiltrating } \\
\text { lymphocytes }\end{array}$ & $0.886(0.383-2.049)$ & 0.776 \\
\hline Regression & $0.892(0.370-2.146)$ & 0.798 \\
\hline BRAF (V600E) mutation & $1.037(0.397-2.709)$ & 0.940 \\
\hline Hemoglobin level & $0.903(0.492-1.657)$ & 0.740 \\
\hline $\begin{array}{l}\text { Serum lactate } \\
\text { dehydrogenase }\end{array}$ & $3.844(2.104-7.020)$ & $<0.001$ \\
\hline Lymph node metastasis & 4.002 (1.396-11.47) & 0.005 \\
\hline $\begin{array}{l}\text { No. of lymph node } \\
\text { metastases }\end{array}$ & $2.729(1.233-6.044)$ & 0.010 \\
\hline Metastatic disease & 8.299 (4.717-14.60) & $<0.001$ \\
\hline Stage of metastatic disease & $1.384(0.647-2.964)$ & 0.398 \\
\hline Response to chemotherapy & $0.268(0.110-0.651)$ & 0.002 \\
\hline $\begin{array}{l}\text { Erythrocyte sedimentation } \\
\text { rate }\end{array}$ & $2.033(1.156-3.577)$ & 0.012 \\
\hline
\end{tabular}

HR, hazard ratio; CI, confidence interval. for survival in melanoma patients and it was associated with other poor prognostic factors. A number of previously reported trials suggested that increased ESR values at presentation may adversely affect prognosis in patients with various types of cancer (2,4-9). Our findings were in agreement with the results reported by these studies. A limited number of our previously performed trials, which included small sample sizes ( $<100$ patients), were focused specifically on melanoma and yielded similar confirmative results (12-15). The P-values in those studies were significantly low, namely $\mathrm{P}<0.001(12,14)$, $\mathrm{P}=0.001$ (13) and $\mathrm{P}=0.002$ (15).

The association of systemic inflammation and patient survival may have implications for immune modulation in melanoma. The correlation of inflammatory status with metastatic disease suggests that melanoma with metastasis may be more immunogenic, thus inducing a more prominent inflammatory response. ESR, as a widely used laboratory test for evaluating the inflammatory status in clinical practice was found to be significantly associated with survival in melanoma patients, suggesting an important role of inflammation in melanoma progression. Inflammatory cells have been suggested to promote carcinogenesis, possibly by augmenting DNA damage, promoting tumor cell proliferation, and stimulating angiogenesis and metastasis.

In conclusion, elevated ESR was found to be associated with metastasis and it predicts worse survival in cutaneous melanoma patients. Therefore, ESR may be a prognostic risk factor and be correlated with other powerful prognostic variables. Despite its relatively low sensitivity and specificity in monitoring disease activity, the ESR assessment is a widely used, cost-effective and simple test, which may be a viable alternative to novel, more expensive methods in the prognostication of cutaneous melanoma patients. The present study was limited by its retrospective design and relatively 
small number of included patients. A prospective study of a larger patient sample is required to confirm the results of the present study.

\section{References}

1. Grivennikov SI, Greten FR and Karin M: Immunity, inflammation, and cancer. Cell 140: 883-899, 2010.

2. Seong MK: Prognostic inflammation score in surgical patients with colorectal cancer. J Korean Med Sci 30: 1793-1799, 2015.

3. Bochen K, Krasowska A, Milaniuk S, Kulczynska M, Prystupa A and Dzida G: Erythrocyte sedimentation rate-an old marker with new applications. J Pre-Clin Clin Res 5: 50-55, 2011.

4. Sengupta S, Lohse CM, Cheville JC, Leibovich BC, Thompson RH, Webster WS, Frank I, Zincke H, Blute ML and Kwon ED: The preoperative erythrocyte sedimentation rate is an independent prognostic factor in renal cell carcinoma. Cancer 106: 304-312, 2006.

5. Chen Z, Malhotra PS, Thomas GR, Ondrey FG, Duffey DC Smith CW, Enamorado I, Yeh NT, Kroog GS, Rudy S, et al: Expression of proinflammatory and proangiogenic cytokines in patients with head and neck cancer. Clin Cancer Res 5 $1369-1379,1999$.

6. Choi ES, Kim HS and Han I: Elevated preoperative systemic inflammatory markers predict poor outcome in localized soft tissue sarcoma. Ann Surg Oncol 21: 778-785, 2014.

7. Eboreime O, Atoe K and Idemudia JO: Erythrocyte sedimentation rate and C-reactive protein levels in breast cancer patients in Benin City, Nigeria. IOSR J Dent Med Sci 14: 116-119, 2015.

8. Strojnik T, Smigoc T and Lah TT: Prognostic value of erythrocyte sedimentation rate and $\mathrm{C}$-reactive protein in the blood of patients with glioma. Anticancer Res 34: 339-347, 2014.

9. Johansson JE, Sigurdsson T, Holmberg L and Bergström R: Erythrocyte sedimentation rate as a tumor marker in human prostatic cancer. An analysis of prognostic factors in 300 population-based consecutive cases. Cancer 70: 1556-1563, 1992.

10. Heimdal K, Hannisdal E and Gundersen S: Regression analyses of prognostic factors in metastatic malignant melanoma. Eur J Cancer Clin Oncol 25: 1219-1223, 1989.
11. Deichmann M, Benner A, Bock M, Jäckel A, Uhl K, Waldmann V and Näher H: S100-Beta, melanoma-inhibiting activity, and lactate dehydrogenase discriminate progressive from nonprogressive American Joint Committee on Cancer stage IV melanoma. J Clin Oncol 17: 1891-1896, 1999.

12. Tas F, Ciftci R, Kilic L, Bilgin E, Keskin S, Sen F, Yildiz I and Yasasever V: Clinical and prognostic significance of coagulation assays in melanoma. Melanoma Res 22: 368-375, 2012.

13. Tas F, Karabulut S, Serilmez M, Yildiz I, Sen F, Ciftci R and Duranyildiz D: Clinical significance of serum M30 and M65 levels in melanoma. Melanoma Res 23: 390-395, 2013.

14. Tas F, Karabulut S, Bilgin E, Tastekin D and Duranyildiz D: Clinical significance of serum fibronectin and vitronectin levels in melanoma patients. Melanoma Res 24: 475-479, 2014

15. Tas F, Bilgin E, Erturk K and Duranyildiz D: Clinical significance of serum claudin-1 levels in melanoma patients. Melanoma Res 26: 377-381, 2016.

16. Westergren A: The technique of the red cell sedimentation reaction. Am Rev Tuberc 14: 94-101, 1926.

17. ICSH recommendations for measurement of erythrocyte sedimentation rate. International Council for Standardization in Haematology (Expert Panel on Blood Rheology). J Clin Pathol 46: 198-203, 1993. 